\section{REGISTRATION OF FIVE PEARL MILLET GERMPLASM SOURCES WITH STABLE RESISTANCE TO RUST}

FIVE pearl millet [Pennisetum glaucum (L.) R.Br.] germplasm accessions; ICML 17 (IP 5030, 700481-21-8) (Reg. no. GP-20, PI 537582), ICML 18 (IP 537 B) (Reg. no. GP-21, PI 537583), ICML 19 (IP 11776) (Reg. no. GP-22, PI 537584), ICML 20 (IP 2084) (Reg. no. GP-23, PI 537585), and ICML 21 (IP 6132, P 24) (Reg. no. GP-24, PI 537586) with stable resistance to rust caused by Puccinia penniset $i$ Zimm. in India; were made available by the ICRISAT in 1984. These accessions also possess moderate to high levels of resistance to downy mildew caused by Sclerospora graminicola (Sacc.) Schroet. in India.

ICML 17, 18, 19, 20, and 21 were selected from bulk germplasm obtained from Nigeria, USA, Mali, India, and Cameroon, respectively. In 1974, bulked seed from the original sources was planted at ICRISAT Center, and single-plant selections showing little or no rust were made. Head-to-row progenies were grown and selections were again made of plants with low rust. This process was repeated three times. Thereafter, the seed was maintained by sibbing plants that were rust free or had low rust, showing a similar phenotype. Rust reactions were assessed from 1977 to 1983 in the International Pearl Millet Rust Nursery (IPMRN), which was operated multilocationally in India. Rust severity was recorded using Cobb's modified scale (1). Data were recorded separately on lower and upper leaves (top four leaves). However, only data from the upper four leaves are presented here, as these leaves likely contribute most to yield (2). All the entries showed high levels of rust resistance across locations and years ( 0 to $13 \%$ mean rust severity on entries compared to 25 to $63 \%$ on susceptible check across the tests).

Accessions showed little or no downy mildew in the multilocational testing. However, they were further evaluated for downy mildew during three postrainy seasons (19851987 ) in the downy mildew nursery at the ICRISAT Center. The plants that developed downy mildew were rejected and only disease-free plants were sibbed. Thus, through continued selection in the downy mildew nursery, levels of downy mildew resistance were likely increased.

At the ICRISAT Center, these accessions are 1 to $2 \mathrm{~m}$ tall, flower in 50 to $60 \mathrm{~d}$ after planting, have panicles 15 to $30 \mathrm{~cm}$ long, and have 2 to 5 tillers plant ${ }^{-1}$. Their seed color is grey to greyish brown, seed shape is hexagonal, globular, obovate, or elliptical and endosperm texture is partly comeous.

Seed stocks of ICML 17 to 21 are being maintained and distributed by ICRISAT, Patancheru, A.P. 502 324, India.

\section{S. D. Singh, ${ }^{*}$ S. B. KING, AND P. Malla Reddy (3)}

\section{References and Notes}

1. Melchers, L.E., and J.H. Parker. 1922. Rust resistance in winter wheat varieties. USDA Bull. 1046.

2. Rao, D.V.M., B.K. Mahalakshmi, and S.M. Ali. 1978. Studies on the relative contribution of various photosynthetic plant parts to the grain development at various moisture levels in Pennisetum typhoides (Burm.) S\&H. Mysore J. Agric. Sci. 12:363-367.

3. Cereals Program, ICRISAT Center, Patancheru, A.P. 502 324, India. Submitted as Journal Article no. 880 by ICRISAT. Registration by CSSA Accepted 31 Jan. 1990. *Corresponding author.

Published in Crop Sci. 30:1165 (1990).

\section{REGISTRATION OF THREE SPRING OAT COMPOSITE GERMPLASMS WITH SHORT PLANT HEIGHT}

PENNCOMP 36 (Reg. no. GP-40, PI 536612), Penncomp 37 (Reg. no. GP-41, PI 536613), and Penncomp 38 (Reg. no. GP-42, PI 536614) spring oat (Avena sativa L.) composites were released by the USDA-ARS and Pennsylvania Agricultural Experiment Station in March 1989. These releases will provide breeders with populations that have a high frequency of genes conditioning semidwarf to moderately short plant height combined with improved kernel characteristics compared to Pennlo semidwarf cultivar and Pennline 6571 germplasm line, previously released from the cooperative program (1). All crosses in the bulk populations had either 'Pennlo', 'Pennline 6571', or Pennlo sibs as parents.

Individual cross populations used to form the composites were advanced through generations in the field near University Park, PA, during which four cycles of mass selection were applied for seed size and weight. Seed lots were first screened to remove small seeds, and the remaining seed was graded with a specific gravity grader. The large-seeded, high specific gravity component (about $10 \%$ by weight) was sown to produce the next cycle. For crosses used to form Penncomp 36 and Penncomp 37, three cycles of mass selection for short plant height also were applied by removing taller tillers soon after full-head with a hedge clipper. Mass selection for short plant height was not applied to the populations for Penncomp 38 because they did not include tall plant types. None of the bulk populations used in the three composites had any significant lodging during $6 \mathrm{yr}$ in field plots.

Penncomp 36 was constituted by compositing seed from nine crosses after the selection cycles were completed. All crosses in this composite had Pennlo semidwarf as a parent and possessed a relatively wide range for kernel size compared to numerous other populations having Pennlo as a parent. Cultivars and lines used in the crosses were: 'Larry', 'Noble', IL75-3389 Sel., Pennline 6571 (semidwarf), PA7967-7907 (CI8447 semidwarf/'Dal'), PA 7967-11644 ('Egdolon 26'/Noble), PA79G252-1 (Egdolon 26/Noble), and PA7836-7543 (Egdolon 26/Jaycee). The PA lines are relatively short and stiff-strawed and have larger seeds than Pennlo. IL75-3389 is a relatively large-seeded line tolerant to barley yellow dwarf virus (BYDV). Larry and Noble both have good kernel characteristics and moderate tolerance to BYDV.

Penncomp 37 was constituted by compositing seed from seven crosses after the selection cycles were completed. All crosses had Pennline 6571 as a parent, and were selected to have variability for desirable kernel characteristics. Cultivars and lines used in the crosses with Pennline 6571 were: Larry, Pennlo (semidwarf), IL75-3389 Sel., MI69-27403, PA783610449 ('James'/CI8447), PA79G252-1 (Egdolon 26/Noble), PA7836-99 (PA Composite 24 selection). PA lines are relatively short and stiff-strawed. MI69-27403 is a tall, relatively large-seeded, high yielding line.

Penncomp 38 was constituted by compositing seed from 23 crosses between sibs of Pennlo semidwarf (Egdolon 26/ 'Otee') or between Pennlo and a sib. All parents were lodging resistant and had moderately small seed size. Sib-mating may have increased the chance of transgressive segregation for larger seed size combined with short plant height and lodging resistance.

Adjacent plots of Pennlo and 'Ogle' grown in 1989 averaged 72 and $110 \mathrm{~cm}$, respectively. Penncomp 36 ranged from 